\title{
Studi tentang kerusakan dan lama perbaikan kapal ikan yang melakukan perbaikan di Bengkel Latih Kapal Perikanan Politeknik Kelautan dan Perikanan Bitung
}

\author{
Study on fishing boat damage and repair duration at Training Station, \\ Bitung Marine and Fisheries Polytechnic \\ I NYOMAN SUBAWA ${ }^{* 1,2}$, EFFENDI P. SITANGGANG ${ }^{1}$ dan JANNY F. POLII ${ }^{1}$ \\ ${ }^{1}$ Program Studi Pemanfaatan Sumberdaya Perikanan, Fakultas Perikanan dan Ilmu Kelautan, \\ Universitas Sam Ratulangi, Manado 95115 \\ ${ }^{2}$ Politeknik Kelautan dan Perikanan Bitung
}

\begin{abstract}
Maintenance is a combination of activities that aim to maintain or to restore equipments into the way they were so they can be used again. This study was conducted in November 2014 until February 2015 in Fishing Boat Training Station, Bitung Marine and Fisheries Polytechnic. This research was done based on a descriptive method on 10 fishing boats under repair. Data was collected through direct observation and interviews. Number of ships repaired in the dock: slight damage 4 ships (40\%), medium damage was 3 ships (30\%), and severe damage 3 ships (30\%). Based on the type of damage, the average duration to repair the ships: slight damage 6 days, medium damage 9 days, and severe damage 45 days.
\end{abstract}

Keywords: damage, repair, repair fisheries, Politeknik KP Bitung

\begin{abstract}
ABSTRAK
Perawatan adalah gabungan dari kegiatan-kegiatan yang bertujuan untuk menjaga atau mengembalikan suatu peralatan menjadi seperti sediakala pada kondisi yang baik untuk dapat dipergunakan kembali. Penelitian ini dilakukan pada bulan November 2014 sampai dengan Februari 2015 di Bengkel Latih Kapal Perikanan milik Politeknik Kelautan dan Perikanan Bitung. Metode yang digunakan adalah metode deskriptif dengan sampel kapal sebanyak 10 kapal ikan yang melaksanakan perbaikan. Teknik pengumpulan data dilakukan dengan cara observasi langsung, dan metode wawancara. Jumlah kapal yang melakukan perbaikan di bengkel: kerusakan ringan 4 unit kapal (40\%), kerusakan sedang 3 unit kapal (30\%), dan kerusakan berat 3 unit kapal (30\%). Lama perbaikan berdasarkan jenis kerusakan kapal adalah kerusakan ringan rata-rata 6 hari, kerusakan sedang rata-rata 9 hari, dan kerusakan berat rata-rata 45 hari.
\end{abstract}

Kata-kata kunci: kerusakan, perbaikan, bengkel perikanan, Politeknik KP Bitung.

\section{PENDAHULUAN}

Kapal perikanan mempunyai masa pakai tertentu. Dalam usaha perikanan tangkap investasi terbesar ditanamkan untuk pengadaan kapal ikan. Agar kapal perikanan dapat dipakai atau dapat bertahan lama, maka umumnya semua kapal perikanan akan memerlukan perawatan atau perbaikan pada periode-periode tertentu.

\footnotetext{
* Penulis untuk penyuratan; email: inyoman.subawa@yahoo.com
}

Menurut Situmorang (2000), Perawatan adalah Pemeliharaan kapal agar selalu dalam keadaan yang siap operasional dan dapat memenuhi jadwal pelayaran kapal yang telah ditentukan tepat pada waktunya, Hal senada juga dikemukakan oleh Soebandono (2006), bahwa Perawatan adalah gabungan dari suatu kegiatan-kegiatan yang bertujuan untuk menjaga atau mengembalikan suatu peralatan menjadi seperti sediakala pada kondisi yang baik, untuk dapat dipergunakan kembali. Lebih lanjut menurut Daryanto (2006), 
Perawatan didefinisikan sebagai suatu usaha kegiatan untuk merawat suatu materil atau mesin agar supaya materil atau mesin itu dapat dipakai secara produktif dan mempunyai umur yang lama.

Tujuan penelitian Mengetahui kerusakan dan lama perbaikan kapal ikan yang melaksanakan perbaikan di bengkel latih kapal perikanan Politeknik Kelautan Bitung.

\section{METODE PENELITIAN}

Penelitian ini menggunakan metode deskriptif dengan Sampel kapal yang diambil dalam penelitian ini berasal dari 10 kapal ikan yang melaksanakan perbaikan di Bengkel Latih Kapal Perikanan Bitung, selama 3 bulan masa penelitian. Metode pengumpulan data dilakukan dengan cara observasi (pengamatan) langsung di lokasi penelitian, dan metode wawancara (interview) dengan bantuan kuesioner.

Tahapan pengumpulan data dilakukan sebagai berikut: mencatat nama, jenis dan ukuran kapal yang naik dok; mencatat waktu (hari, tanggal) dari setiap kapal yang naik dok; mencatat jenis-jenis kerusakan setiap kapal yang naik dok; mencatat waktu yang diperlukan untuk perbaikan menurut tingkat kerusakan; dan menghitung jumlah ratarata waktu yang diperlukan dalam perbaikan kapal sesuai dengan jenis kerusakan. Pengolahan data lama perbaikan menggunakan metode analisis statistik rataan tunggal yang menurut Supranto (2000):

dengan

$$
\bar{X}=\frac{\sum_{1}^{n} X_{i}}{n}
$$

$X_{i}=$ Lama perbaikan kapal ke- $i$ yang masuk ke bengkel kapal

$n=$ jumlah kapal (jumlah sampel)

$i=1,2,3, \ldots, n$

\section{HASIL DAN PEMBAHASAN}

Bengkel Latih Kapal Perikanan Politeknik Kelautan dan Perikanan Bitung menggunakan jenis kontruksi slipway atau dock tarik yang menggunakan mesin winch daya listrik. Slipway adalah fasilitas perbaikan kapal dengan cara mendudukkan kapal di atas kereta yang disebut trolley dan menarik kapal tersebut dari permukaan air dengan mesin. Secara umum proses kerja untuk slipway dock atau biasa disebut dock tarik, hampir sama dengan jenis dock yang lain. Perbedaannya adalah kapal dinaikkan ke atas slipway kemudian ditarik ke darat agar dapat dilakukan proses docking.

\section{Sarana utama}

Adapun komponen utama dalam melaksanakan kegiatan dock di Politeknik Kelautan dan Perikanan Bitung adalah sebagai berikut:

- Generator, digunakan untuk menghasilkan tenaga listrik untuk menggerakkan motor winch.

- Mesin derek (winch), alat yang digunakan untuk menarik kapal pada saat akan naik di atas rel serta berfungsi juga untuk menurunkan kapal dari atas rel sebelum diluncurkan ke atas permukaan air.

- Kereta dan rel, kereta dapat digunakan sebagai tempat dudukan kapal sebelum kapal tersebut di tarik ke atas galangan/rel. Sedangkan untuk rel sebagai landasan tempat berputarnya rodaroda yang terdapat pada kereta, dan

- Kompressor, komponen yang sangat penting dalam melaksanakan proses menaikkan dan menurunkan kapal, yaitu sebagai alat bantu pernafasan yang digunakan oleh penyelam di bawah permukaan air pada saat mengatur posisi kapal di atas kereta dan pada saat pemasangan kayu bantalan/baji.

\section{Sarana penunjang}

Dalam rangka memberikan layanan optimal terhadap pelanggan (pemilik kapal), bengkel menyediakan fasilitas-fasilitas penunjang agar kegiatan perbaikan dan perawatan kapal dapat berjalan sesuai waktu yang telah di rencanakan.

\section{Standar Operasional Prosedur}

Standar Operasional Prosedur (Standard Operating Prosedure, SOP) adalah serangkaian instruksi tertulis yang dibakukan (terdokumentasi) mengenai berbagai proses penyelenggaraan administrasi perusahaan, bagaimana dan kapan harus dilakukan, di mana dan oleh siapa dilakukan. SOP adalah serangkaian instruksi yang menggambarkan pendokumentasian dari kegiatan yang dilakukan secara berulang pada sebuah organisasi

\section{Tahapan dan jenis perbaikan kapal}

Tahapan perbaikan kapal meliputi persiapan, proses naik galangan (dock), dan proses penurunan kapal. Jenis-jenis pekerjaan perawatan dan perbaikan yang dilakukan saat kapal berada di atas dock selama penelitian adalah pembersihan/skrap body kapal, cuci dengan air tawar, perbaikan 
bagian lambung kapal yang mengalami kerusakan, pemakalan, melapisi lunas kapal dengan menggunakan plat baja, melapisi lambung kapal dengan fiberglass, pengecatan anti fouling (AF), overhoul propeller, penggantian as propeller, dan penggantian pokhout.
Kapal ikan yang melaksanakan perbaikan di Politeknik Kelautan dan Perikanan Bitung dari bulan November 2014 sampai dengan Februari 2015 berjumlah 10 unit kapal (Tabel 1). Kapal yang melaksanakan perbaikan dapat digolongkan berdasarkan jenis kerusakan seperti pada Tabel 2 .

Tabel 1. Data kapal ikan yang melaksanakan perbaikan dari bulan November 2014 sampai dengan Febuari 2015

\begin{tabular}{rlllccc}
\hline No. & \multicolumn{1}{c}{ Nama Kapal } & GT & Jenis kapal & $\begin{array}{c}\text { Tanggal } \\
\text { Naik }\end{array}$ & $\begin{array}{c}\text { Tanggal } \\
\text { Turun }\end{array}$ & $\begin{array}{c}\text { Lama } \\
\text { Perbaikan } \\
\text { (hari) }\end{array}$ \\
\hline 1. & KM. Glori & 25 & Kayu & $06-11-14$ & $19-01-15$ & 73 \\
2. & KM. Tetap Setia 3 & 28 & Kayu & $10-11-14$ & $17-12-14$ & 37 \\
3. & KM. Sahabat Nusantara & 40 & Kayu & $17-12-14$ & $23-12-14$ & 6 \\
4. & KM. Yasin 01 & 28 & Kayu & $23-12-14$ & $31-12-14$ & 8 \\
5. & KM. Jaya Samudera & 28 & Kayu & $20-01-15$ & $14-02-15$ & 25 \\
6. & KM. Sahabat -01 & 28 & Kayu & $21-01-15$ & $01-02-15$ & 11 \\
7. & KM. Efrata & 23 & Kayu & $10-02-15$ & $18-02-15$ & 8 \\
8. & KM. Hosana & 10 & Kayu & $14-02-15$ & $18-02-15$ & 4 \\
9. & KM. Nurjaya Adi & 28 & Kayu & $18-02-15$ & $25-02-15$ & 7 \\
10. & KM. Coelachant & 28 & Fiberglass & $20-02-15$ & $25-02-15$ & 5 \\
\hline
\end{tabular}

Sumber : Bengkel Latih kapal Perikanan Politeknik KP Bitung, 2015

Tabel 2. Tabel penggolongan kerusakan kapal berdasarkan jenis kerusakan

\begin{tabular}{|c|c|c|c|c|c|c|c|c|c|c|c|c|c|c|}
\hline \multirow[t]{2}{*}{ No. } & \multirow[t]{2}{*}{ Nama Kapal } & \multicolumn{11}{|c|}{ Jenis Kerusakan } & \multirow[t]{2}{*}{ Jumlah } & \multirow[t]{2}{*}{ Kriteria } \\
\hline & & 1 & 2 & 3 & 4 & 5 & 6 & 7 & 8 & 9 & 10 & 11 & & \\
\hline 1. & KM. Glori & $\sqrt{ }$ & $\sqrt{ }$ & $\sqrt{ }$ & $\sqrt{ }$ & $\sqrt{ }$ & $\sqrt{ }$ & $\sqrt{ }$ & $\mathrm{X}$ & $\sqrt{ }$ & $\sqrt{ }$ & $\sqrt{ }$ & 58 & Berat \\
\hline 2. & KM. Tetap Setia 3 & $\sqrt{ }$ & $\sqrt{ }$ & $\sqrt{ }$ & $\sqrt{ }$ & $\sqrt{ }$ & $\sqrt{ }$ & $\sqrt{ }$ & $\sqrt{ }$ & $\sqrt{ }$ & $X$ & $X$ & 45 & Berat \\
\hline 3. & KM.Sahabat Nusantara & $\sqrt{ }$ & $\sqrt{ }$ & $\sqrt{ }$ & $\sqrt{ }$ & $\sqrt{ }$ & $\sqrt{ }$ & $\mathrm{X}$ & $\mathrm{X}$ & $X$ & $\mathrm{X}$ & $\mathrm{X}$ & 21 & Ringan \\
\hline 4. & KM. Yasin 01 & $\sqrt{ }$ & $\sqrt{ }$ & $\sqrt{ }$ & $\sqrt{ }$ & $\sqrt{ }$ & $\sqrt{ }$ & $\sqrt{ }$ & $\mathrm{X}$ & $\mathrm{X}$ & $\mathrm{X}$ & $\mathrm{X}$ & 28 & Sedang \\
\hline 5. & KM. Jaya Samudera & $\sqrt{ }$ & $\sqrt{ }$ & $\sqrt{ }$ & $\sqrt{ }$ & $\sqrt{ }$ & $\sqrt{ }$ & $\sqrt{ }$ & $\sqrt{ }$ & $\sqrt{ }$ & $\sqrt{ }$ & $\mathrm{X}$ & 55 & Berat \\
\hline 6. & KM. Sahabat -01 & $\sqrt{ }$ & $\sqrt{ }$ & $\sqrt{ }$ & $\sqrt{ }$ & $\sqrt{ }$ & $\sqrt{ }$ & $\sqrt{ }$ & $X$ & $X$ & $\mathrm{X}$ & $X$ & 28 & Sedang \\
\hline 7. & KM. Efrata & $\sqrt{ }$ & $\sqrt{ }$ & $\sqrt{ }$ & $\sqrt{ }$ & $\sqrt{ }$ & $\sqrt{ }$ & $X$ & $X$ & $X$ & $X$ & $X$ & 21 & Ringan \\
\hline 8. & KM. Hosana & $\sqrt{ }$ & $\sqrt{ }$ & $\sqrt{ }$ & $\mathrm{X}$ & $\sqrt{ }$ & $\sqrt{ }$ & $\mathrm{X}$ & $\mathrm{X}$ & $X$ & $X$ & $X$ & 17 & Ringan \\
\hline 9. & KM. Nurjaya Adi & $\sqrt{ }$ & $\sqrt{ }$ & $\sqrt{ }$ & $\sqrt{ }$ & $\sqrt{ }$ & $\sqrt{ }$ & $\sqrt{ }$ & $\sqrt{ }$ & $\mathrm{X}$ & $\mathrm{X}$ & $\mathrm{X}$ & 32 & Sedang \\
\hline 10. & KM. Coelachant & $\sqrt{ }$ & $\sqrt{ }$ & $X$ & $\sqrt{ }$ & $\sqrt{ }$ & $\mathrm{X}$ & $\sqrt{ }$ & $\mathrm{X}$ & $X$ & $X$ & $X$ & 19 & Ringan \\
\hline
\end{tabular}

Sumber: Bengkel Latih Kapal Perikanan Politeknik KP Bitung (2015)

Catatan $: \sqrt{ }=$ dilakukan, $X=$ tidak dilakukan

Keterangan Jenis Pekerjaan:
1. Pengecetan
2. Skrap dan cuci kapal
3. Pemakalan dan pendempulan
4. Ganti pokhout
5. Perbaikan/penggantian daun kemudi
6. Penggantian lambung dan dek kapal

7. Center/ganti as

8. Laminating/fiberglass bodi kapal

9. Melapisi lunas dengan plat baja

10. Perbaikan/penggantian propeller

11. Overhoul mesin 
Dari data penelitian kerusakan kapal yang naik dock dari bulan November 2014 sampai dengan Febuari 2015 yang berdasarkan jenis perbaikan didapatkan: kerusakan ringan 4 unit kapal, kerusakan sedang 3 unit kapal, dan kerusakan berat 3 unit kapal, dengan persentase: kerusakan ringan 40 $\%$, kerusakan sedang $30 \%$, dan kerusakan berat $30 \%$.
Kapal ikan yang melaksanakan perbaikan di bengkel berjumlah 10 unit dengan konstruksi bangunan berbahan kayu 9 kapal dan fiberglass 1 kapal, dengan ukuran 10-40 GT, dengan jenis kapal penangkap dan penampung. Waktu yang dibutuhkan dalam perbaikan mulai 4 hari hingga 73 hari sesuai dengan skala kerusakan.

Tabel 3. Data jumlah kapal ikan yang melaksanakan perbaikan dari bulan November 2014 sampai dengan Febuari 2015.

\begin{tabular}{|c|c|c|c|c|c|}
\hline No. & Nama Kapal & GT & Jenis kapal & $\begin{array}{c}\text { Lama } \\
\text { perbaikan } \\
\text { (hari) }\end{array}$ & $\begin{array}{c}\text { Jenis } \\
\text { Kerusakan }\end{array}$ \\
\hline 1. & KM. Glori & 25 & Kayu & 73 & Berat \\
\hline 2. & KM. Tetap Setia 3 & 28 & Kayu & 37 & Berat \\
\hline 3. & KM. Sahabat Nusantara & 40 & Kayu & 6 & Ringan \\
\hline 4. & KM. Yasin 01 & 28 & Kayu & 8 & Sedang \\
\hline 5 . & KM. Jaya Samudera & 28 & Kayu & 25 & Berat \\
\hline 6. & KM. Sahabat -01 & 28 & Kayu & 11 & Sedang \\
\hline 7. & KM. Efrata & 23 & Kayu & 8 & Ringan \\
\hline 8 . & KM. Hosana & 10 & Kayu & 4 & Ringan \\
\hline 9. & KM. Nurjaya Adi & 28 & Kayu & 7 & Sedang \\
\hline 10. & KM. Coelachant & 28 & Fiberglass & 5 & Ringan \\
\hline
\end{tabular}

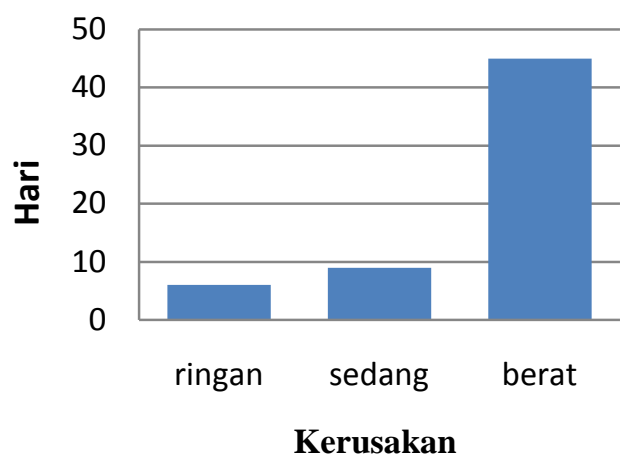

Gambar 4. Diagram lama perbaikan kapal berdasarkan jenis kerusakan dari bulan November 2014 sampai dengan Februari 2015

Berdasarkan analisis data menggunakan rumus rataan data tunggal, diperoleh rata-rata lama perbaikan sebagai berikut: kerusakan ringan 6 hari, kerusakan sedang 9 hari, dan kerusakan berat 45 hari. Dengan mengetahui jenis kerusakan kapal, maka dapat diperkirakan berapa lama kapal-kapal itu akan melaksanakan perbaikan.

\section{KESIMPULAN}

Berdasarkan hasil penelitian yang telah dilaksanakan, maka dapat disimpulkan bahwa kerusakan kapal yang melakukan perbaikan di Bengkel Latih Kapal Perikanan Politeknik Kelautan dan Perikanan Bitung dari bulan November 2014 sampai dengan Februari 2015: kerusakan ringan 4 unit kapal (40\%), kerusakan sedang 3 unit kapal (30 $\%)$, dan kerusakan berat 3 unit kapal (30\%); lama perbaikan berdasarkan jenis kerusakan kapal yang yang melaksanakan perbaikan: kerusakan ringan rata-rata 6 hari, kerusakan sedang rata-rata 9 hari, dan kerusakan berat rata-rata 45 hari.

\section{DAFTAR PUSTAKA}

Daryanto. 2006. Dasar-Dasar Teknik Mobil. PT. Bumi Aksara, Jakarta.

Soebandono, P. 2006. Pengertian perawatan. Manajemen Perawatan kapal

Situmorang, 2000, Pengertian perawatan. Manajemen Perawatan kapal

Supranto, J. 2000. Statistik Teori dan Aplikasi. Erlangga, Jakarta. 